of aluminium, about $10 \mathrm{cms}$. long and $\mathrm{I} \frac{1}{2} \mathrm{cms}$. wide, cut from the same sheet as the surrounding aluminium tube, was supported at one end by a small piece of paraffin so placed as to be out of reach of the action of the Röntgen lamp. The rays from the lamp were allowed to pass from a lead cylinder surrounding it by a small hole about 3 of a square $\mathrm{cm}$. in area. They fell on the aluminium sheath transparent to them, and rendered the air between it and the insulated aluminium within conductive.

We tried various-differences of potential, ranging from a few volts to 2200 volts. In one series of experiments we charged the insulated metal to $-97{ }^{\circ} 5$ volts, and then disconnected the battery electrodes. The lamp was then set a-going, and the electrometer deviation taken each half-minute for a minute and a half with one pair of quadrants insulated. The rays were then stopped, the quadrants metallically connected, and metallic zero again found. Then the reading during another period of one and a half minutes, with the rays acting, was observed, and so on until no deviation from the metallic zero of the electrometer was found with one pair of quadrants insulated, and the rays falling on the aluminium outside coating of the Leyden A. The sensibly complete discharge thus observed took place in abo.t a quarter of an hour. We found that the rate of deviation from the metallic zero was the same as the difference of potential fell from -97.5 volts to about -4 volts. With differences of potential of $-930,-1750$, and -2000 volts the rate of deviation was not appreciably greater than with \pm 20 volts.

This confirms and extends, through a very wide range of voltage, the interesting and important discovery announced by J. J. Thomson and McClelland, in their paper in the Cambridge Philosophical Society Proceedings of March I896, to the effect that the conduction of electricity through air under influence of the Röntgen rays is almost independent of the electric pressure when it exceeds a few volts per centimetre.

In the experiments on paraffin, the outside coating of the Leyden A consisted of an aluminium cylinder $27 \mathrm{cms}$. long, $4 \mathrm{cms}$. diameter, connected to sheaths. A metal bar about I 75 cms. in diameter, and $30 \mathrm{cms}$. long, supported centrally on paraffin filling the whole space between it and the aluminium sheath, constituted the inside coating. With this arrangement we made experiments with differences of potential of $\pm 94, \pm 119, \pm 238,-2000,+2500$, and -2400 volts. At none of these potentials did we find any perceptible increase of conductance produced by the Röntgen rays above the natural conductance of the paraffin when undisturbed by them.

In the experiments with glass, the Leyden A consisted of a glass tube silvered on the inside. The inside silvering was placed in metallic connection with the inside coating of $B$. That part of the glass tube which projected beyond the lead sheath was covered with wet blotting-paper connected to the sheaths. We observed the behaviour of glass under the Röntgen rays at differences of potential of $+800,+1500$, +2000 volts. We found no indication of increased conductance due to the rays at these voltages.

We are forced to conclude that the experiments described by J. J. Thomson and McClelland do not prove any conductance to be induced in paraffin or glass by the Röntgen rays. It seems to us probable that the results described in their paper -pages 7 and 8 -are to be explained by electrifications induced on surfaces of glass or of paraffin in contact with air rendered temporarily conductive by the Röntgen rays.

\section{THE INTRODUCTION OF BENEFICIAL}

\section{INSECTS INTO THE HAWAIIAN ISLANDS. ${ }^{1}$}

$\mathrm{FEW}$ countries have been more plagued by the importation of insect pests than the Hawaiian Islands; in none have such extraordinary results followed the introduction of beneficial species to destroy them. By far the most conspicuous of the former class, and hitherto the most injurious, have been the scale-insects. The number of species of this group, which have spread throughout the islands, is remarkable, and not less so the enormous multiplication of individuals of many or most of these species.

1 Notes on the result of introducing predatory and parasitic insects into the Hawaiian Islands for beneficial purposes. Communicated by the Secretary of the Committee, appointed by the Royal Society and British Association, for investigating the Fauna of the Sandwich Islands.

No. I 430 , voL. 55$]$
The first importation of Coccinelizde to destroy these hordes was made in 1890 , when Vedalia cardinalis, Muls., a native of Australia, was sent over by Mr. Albert Koebele. At that time many trees were in a deplorable condition from the attacks of Icerya, monkey-pod trees being particularly badly infested-so much so that they were being largely cut down, as the only resource. The Vedalia was a complete success; it became perfectly naturalised, increased prodigiously for a time, practically cleared the trees, and then, as the Icery a became comparatively scarce, decreased in numbers; while at the present time it is evident that the number of the scale and its destroyer has arrived at a fixed proportion. Previously to its introduction here the same ladybird had done excellent service in the fruit orchards of Lower California.

The complete success of this first experiment was followed by the engagement of Mr. Koebele by the IHawaiian Government and planters for a term of years, to contend against other plagues no less serious than the Icerya. The wisdom of this course cannot be too highly commended, when compared with the indifference shown by the countries similarly circumstanced, and is a set-off against the reckless importation of infected plants which had been allowed in former years. Mr. Koebele, after seeing the wants of the country, with his unrivalled knowledge of the habits of Coccinellida, introduced numbers of other species in 1894, many of which, no doubt, failed to establish themselves, while a considerable number (how many is yet uncertain) have become completely naturalised, and done splendid service.

Before mentioning these, it may be said that the two chief products of the islands are sugar (which until lately has been far the most important export) and coffee, the cultivation of which has lately enormously increased. There is also a considerable amount of fruit grown; and this, too, is lately increasing. All these industries have been continually threatened with destruction from imported insects. The Rev. T. Blackburn, who studied the insects of the islands during six years-now nearly twenty years ago-wrote that the fruit trees were afflicted with incurable blight. Coffee plants were introduced in 1825 . Its cultivation formed quite an industry in the middle of the century on Kauai, where only it was systematically cultivated; its growth was finally abandoned there in 1856 , owing to the ravages of blight, said to have been imported in 1850 . The sugar-cane has been, and is, attacked not only by scale-insects and Aphides, but by several other creatures of quite different orders.

To return now to the ladylirds : one of the most useful has been Coccinella repanda, Thun. (from Ceylon, Australia, China, \&c.) which feeds on Aphides. The services of this species cannot be over-estimated. On Kauai recently the cane was so much attacked by an $A$ phis as to cause considerable alarm. On visiting the locality the Coccinella was found to be already present, breeding in such numbers as to leave little doubt that the plants would be soon cleared. On the same island, on another occasion, I saw the fruit trees (especially orange and lime) in a beautiful garden in a most deplorable condition from the attacks of $A$ phis and scales. Very few ladybirds could be found after a careful search. The owner was for spraying the trees, but, seeing their condition could not be much worse, I advised him to wait and give the beetles a chance. In a few weeks these were swarming; and when I returned, after six months, the infested trees were all in perfect condition, full of fruit and flower. Not less numerous than the preceding is a Cryptolcemus (C. montrouzieri) introduced from Australia, and thoroughly naturalised. It attacks the highly injurious species of Pulvinaria. When I visited the Kona district of Hawaii in I892, many of the trees were literally festooned with the masses of this pest, and appeared on the point of being totally destroyed. In 1894 the ladybirds were sent there, and very soon had entirely changed the condition of things, and the affected trees speedily recovered. To show the vast increase of this species of ladybird, I may state that in June of the present year, many large trees in the city of Honolulu had several square feet of their bark entirely hidden by the larvæ, which formed great white masses, presenting such an extraordinary appearance that I much regret not having obtained photographs of some of the trees. At the present time this species and Coccinella repanda are far the most conspicuous and abundant of the introduced Coccinellida, either of them far outnumbering even the most abundant native insects. Their wide distribution is remarkable, for not only are they all over the lowlands, but throughout the mountain forests as high as four or five thousand feet above sea. level ; indeed, the Coccinella is still higher t:p beyond the limits of 
the forest proper. Other introductions, some of which are extremeiy abundant, may be briefly noticed. The beautiful Orizus chalybeus, from Australia, is now widely spread and very common, feeding on Lecanium, Pulvinaria, Diaspis, \&c. Rhizobius ventralis, Muls., from China and Ceylon, attacks that most abundant scale Lecanium longulum, and other species. Chilocorus circumdatus, from China and Ceylon, breeds freely on scales in Honolulu. Trees literally covered with Mytilaspis were entirely cleaned. Even the old dry scales were turned over in the search for food. Platyonus lividigaster has bred freely on orange Aphis in the city. Scymnus debilis, which in California feeds on Daitylopius, has become entirely naturalised. Other introductions, which have bred in the Islands, are Chilocorus bivulnerns, Leis conformis, Synonyche grandis, and Novius Koebelei (Fig., Rep. on Import. of Par. and Pred. Ins., by State Board of Horticulture, Sacramento, I892.) There is little doubt that other introduced species will turn up, when the city gardens and suburbs are systematicallysearched. Before the introduction of the species above mentioned, the only known Hawaiian Coccinellidic were a few species (probably endemic) of Scymmis and Coccinella abdominalis, the latter, no doubt, accidentally imported from America many years ago. Unfortunately this species is attacked by a hymenopterous parasite, a Braconid, Centistes americana, Riley, which may interfere with the splendid work of $C$ repanda. The presence of this parasite is the more to be deplored, as such care was taken to exclude parasitised specimens when the introductions were made. This was very necessary, as the ladybirds seem very liable to the attack of parasitic Hymenoptera, especially the Australian species.

It is very pleasing to be able to refer to such successful results in the Hawaiian Islands, as in the United States Mr. Koebele's work has met with a good deal of adverse criticism. But it is not only by the introduction of ladybirds that $\mathrm{Mr}$. Koebele has done such signal service, for he has had many other insect pests to contend with, which it is beyond the power of these to affect, attacking, as they do, but a very small portion of the insect world. In many parts of the islands, the bananas and palm-trees have been severely attacked by the larva of a species of Pyralidina. There is little doubt that in course of time this plague will be entirely kept under by a fine Chalcid (Chalcis obscurata, Walk.), introduced from China and Japan, which has already multiplied enormously at the expense of these caterpillars-so much so, indeed, that in many localities the trees have now entirely recovered. Again, within the last few years a Lamellicorn beetle (Adoretus umbrosus) has been introduced from Japan. This insect speedily multiplied prodigiously, and soon destroyed nearly every rose-tree in HonoIulu, and subsequently attacked the foliage of many other trees. The cultivation of roses-once a feature of the city-became impossible, while a remedy seemed hopeless. One day, however, Mr. Koebele discovered a parasitic fungus, and by cultivation of this, and infecting healthy beeties, soon spread it far and wide. Whether the fungus will prove entirely effective is not at present certain, but in any case it will be a most useful aid. The writer has seen the ground under trees which were attacked, literally strewn with dead beetles-all killed by the fungusand beneath the surface of the soil the larva had likewise perished. It is at least certain, therefore, that myriacls of the beetles were destroyed very shortly after the fungus was spread around by the individuals that had been infected.

It becomes natural to ask why the success of the imported beneficial insects has been so pronounced here, while in other countries it has been attained in a comparatively small measure. The reason, I think, is sufficiently obvious. The same causes which have led to the rapid spread and excessive multiplication of injurious introductions, have operated equally on the beneficial ones that prey upon them. The remote position of the islands, and the consequently limited fauna, giving free scope for increase to new arrivals, the general absence of creatures injurious to the introduced beneficial species, and the equability of the climate, allowing of almost continuous breeding, may well afford result which could hardly be attained elsewhere on the globe. The keen struggle for existence of continental lands is comparatively non-existent, and, so far as it exists, is rather brought about by the introduced fauna than by the native one.

In conclusion, I cannot help turning to the darker side of the picture. What will be the result of all these importations on the endemic fauna? The introduction of many other species-

1 Since writing the above several other species have been found, which have evidently bred in the country.

NO. 143 O, VOL. 55$]$ parasitic and predaceous-is contemplated, and will be performed. That success, from an economic point of view, will be attained there is little doubt, and while industries are threatened, or even the gratification of æsthetic tastes, it is certain that no consideration will be given to the native fauna. When even now the ladybirds are affecting the latter, what will be the result of the introduction of more widely predaceous species? The effect of the former is not imaginary, but proven. In June I 895, in a lovely forest in Hawaii-5000 feet above sea-level-I found the native trees much affected by a black Aphis. By beating these trees the blight came down in abundance, and amongst them various fine species of endemic Chrysopa and Hemerobius, predatory crealures. One or two introduced ladybirds were also noticed. By September the ladybirds were in thousands, the blight and native insects in small numbers. In August I896 not an Aphis was to be found, and only one or two stray specimens of ladybirds, as one may find anywhere throughout the forests. They had done their work and disappeared. 'This is a high testimonial as to the capabilities of the beetles, and as the existence or non-existence of Hawaiian Chrysopa is not likely to be regarded by people at large, and seeing that sooner or later the greater part of this most interesting native fauna is, under any circumstances, in all probabulity doomed to extinction, it only remains to wish Mr. Koebele a success in the future equal to that which he has already attained.

Honolulu, H.I., November $1896 . \quad$ R. C. L. Perkins.

\section{MARINE ORGANISMS AND THE CONDI- TIONS OF THEIR ENVIRONMENT.}

THE ocean may be divided into two great biological regions, viz. the superficial region, including the waters between the surface and a depth of about Ioo fathoms, and the deep-sea region extending from the 100 fathoms line down to the greatest depths. The superficial region may be subdivided into two provinces, viz. the shallow-water or neritic province around the land masses where the depth is less than Ioo fathoms, and the pelagic province, embracing the superficial waters of the ocean basins outside the 100 fathoms line; these two provinces contrast sharply as regards physical conditions, which are of great variety in the neritic province, and very uniform over wide areas in the pelagic province.

Temperature is a more important factor in determining the distribution of marine organisms, mostly cold-blooded, than in the case of terrestrial species, mostly warm-blooded and air breathing animals, the distribution of which depends rather upon topographical features than upon climatic conditions.

A map was exhibited showing the range of temperature in the surface waters of the ocean all over the world, and indicated northern and southern circumpolar areas with a low tempera. ture and small range (under $10^{\circ} \mathrm{F}$.), and an almost circum. tropical area with a similar small range but high temperature; in temperate regions the range is greater, the areas of greates range (over $4 \mathrm{O}^{\circ} \mathrm{F}$.) being found off the eastern coasts of North America and of Asia and south of the Cape, due to the mixture of currents from different sources, which sometimes causes the destruction of enormous numbers of marine invertebrates and fishes.

The pelagic tropical waters of the ocean teem with various forms of life, of which probably 70 to 80 per cent. function as plants, converting, under the influcnce of sunlight, the inorganic constituents of sea-water into organic compounds, thus forming the original source of food of marine animals both at the surface and at the bottom of the sea.

The number of species living in the pelagic waters of the tropics may greatly exceed the number in polar waters, where, on the other hand, there is often a great development of individuals, so that there is probably a greater bulk of organic matter in the cold polar waters than in the warm tropical waters. The rate of animal metabolism is slower at a low than at a high temperature, and organisms inhabiting tropical waters probably pass through their life-history much more rapidly than similar organisms living in polar regions. Carbonate-of-lime-secreting organisms are most abundant in the warm tropical waters, decreasing in numbers towards the polar regions, and it has been shown that the precipitation of carbonate of lime from solution in sea-water takes place much more rapidly at a high

1 An address delivered at the Royal Institution by Dr. John Murray, F.R.S. 